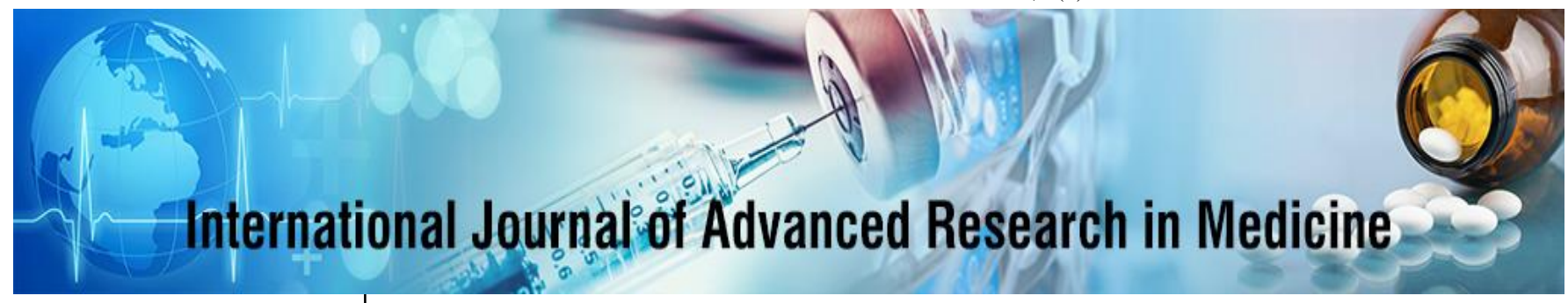

E-ISSN: 2706-9575

P-ISSN: 2706-9567

IJARM 2019; 1(1): 31-33

Received: 15-01-2018

Accepted: 17-02-2018

\section{Dr. Prashanti N}

Associate Professor,

Department of Anatomy,

Kanachur Institute of Medical

Sciences, Mangalore,

Karnataka, India
Corresponding Author:

Dr. Prashanti N

Associate Professor,

Department of Anatomy,

Kanachur Institute of Medical

Sciences, Mangalore,

Karnataka, India

\section{Clinical case based learning vs routine teaching in anatomy: A cross sectional perception and result based study}

\section{Dr. Prashanti N}

DOI: https://doi.org/10.22271/27069567.2019.v1.i1a.176

\begin{abstract}
Anatomy is a pre-clinical subject, which is taught in Ist year of MBBS. According to current curriculum the subject is mainly taught in classroom setting and very less exposure to clinical application and hospital based real life situations. It makes subject very insipid and students do not understand the utilization of subject during their actual practice. Clinical application based learning involves clinical projects that incorporate complex tasks, based on challenging questions or problems that involve students in design, problem-solving, decision-making, or investigative activities; give students the opportunity to work relatively autonomously over extended periods of time; and culminate in realistic products or presentations. This study puts in an effort to find the superior of the two ways of clinical teaching. The first being the case based learning and the second being the project based learning.
\end{abstract}

Keywords: case - based, project based, medical, curriculum

\section{Introduction}

Students have pressed out the need for clinical application based learning to understand the role in clinical circumstances ${ }^{[1]}$. In vision 2015, given by the Medical Council of India, more emphasis given to the active learning through newer teaching learning methods which involve student's participation ${ }^{[2]}$. Active learning enhances learning and thus generally improves the quality of medical education ${ }^{[3]}$. According to new curriculum the subject is mainly taught in classroom setting and very less exposure to clinical application and hospital based real life situations. It makes subject very insipid and students do not understand the utilization of subject during their actual practice. Clinical application based learning involves clinical projects that incorporate complex tasks, based on challenging questions or problems that involve students in design, problem-solving, decision-making, or investigative activities; give students the opportunity to work relatively autonomously over extended periods of time; and culminate in realistic products or presentations ${ }^{[4]}$. The effort toward developing active learning was based on meaningful learning which ensures understanding and applying concepts rather than memorizing only which is rote learning ${ }^{[5-10]}$. Meaningful learning involves the acquisition of "useful" knowledge so that it can be accessed from different starting points and has to correlate with previous knowledge with multiple representations.

This study puts in an effort to find the superior of the two ways of clinical teaching. The first being the case based learning and the second being the project based learning.

\section{Aims and Objectives}

To find the superior of the two clinical teaching methods.

\section{Materials and Methods}

1. Design: Interventional study

2. Settings: Study was done in the Department of Anatomy, Kanachur Institute of Medical Sciences, Mangalore

3. Subjects: III year MBBS Students 2016 batch.

4. The study was done from Aug 2016 to Sept 2017

5. Sample Size: 150 students divided into 2 groups of 75 each by stratified randomized method. 
6. Intervention: Clinical case based vs routine teaching.

7. Tools: Validated Questionnaire and Validated MCQ

\section{Inclusion Criteria}

$3^{\text {rd }}$ MBBS students of 2018 batch

\section{Exclusion Criteria}

Those students who have not given valid consent and who were absent for one class or for assessment.

\section{Statistical Analysis}

Statistical significance of comparison of post test scores obtained immediately by two teaching learning methods was analysed using unpaired t test. Statistical significance of comparison of post test scores obtained after 30 days by two teaching learning methods was analysed using unpaired $\mathrm{t}$ test. Descriptive data was expressed as percentage for perception. Mann Whitney $U$ test was used to compare perception between two groups. Also unpaired t test was done to analyse the perception between two groups.

\section{Results}

Table 1: Pre test

\begin{tabular}{|c|c|c|c|c|c|}
\hline Group & Pre Test & $\mathbf{N}$ & $\begin{array}{c}\text { Mean } \\
\text { scores }\end{array}$ & $\begin{array}{c}\text { Std. } \\
\text { Deviation }\end{array}$ & P Value \\
\hline CBL group & MCQ & 70 & 1.56 & 1.95 & \multirow{2}{*}{$>0.001$} \\
\hline Routine teaching & MCQ & 70 & 1.13 & 1.07 & \\
\hline
\end{tabular}

There is no significant difference between the two groups.

Table 2: independent $t$ test to compare between the two groups

\begin{tabular}{|c|c|c|c|c|c|}
\hline & Group & $\mathbf{N}$ & Mean & Std. Deviation & \multirow{2}{*}{ P VALUE } \\
\hline \multirow{2}{*}{ Perception } & Routine & 70 & 36.98 & 6.84 & \multirow{2}{*}{$<\mathbf{0 . 0 0 1}$} \\
\cline { 2 - 6 } & CBL & 70 & 47.98 & 1.98 & \\
\hline \multirow{2}{*}{ MCQ } & Routine & 70 & 3.98 & 1.76 & \multirow{2}{*}{$<\mathbf{0 . 0 0 1}$} \\
\cline { 2 - 5 } & CBL & 70 & 7.85 & 1.12 & \\
\hline \multirow{2}{*}{ MCQ-After 15 days } & Routine & 70 & 3.44 & 2.57 & \multirow{2}{*}{$<\mathbf{0 . 0 0 1}$} \\
\cline { 2 - 5 } & CBL & 70 & 7.53 & 1.16 & \\
\hline
\end{tabular}

\section{Discussion}

In our study there is a significant difference between the perception scores. The students were better interested in the clinical based learning.

There is also a clear cut significance test difference between the marks scored between the two groups in terms of MCQs and when the test was conducted after 15 days, even in that the students who underwent clinics based teaching excelled. In CBL and routine teaching, a real world scenario with the supporting data and documents is given with open ended questions and the case content is closely aligned with the overall instructional goals and objectives. This certainly gives learner an opportunity to develop their own understanding and self-directed learning, combined with dialogue with their teachers and peers. We found that CBL was more interesting than but the success rate was more in routine teaching. Participants enjoyed as they were given a challenging task which they could solve independently and work on these with teachers and others. As per the feedback, adult learners were willing to learn in safe learning environment. As the students are passive learners in traditional teaching method, whereas in CBL one has to actively participate in group activity by increasing the group interaction. Team work is a principle of adult learning as well as an effective practice. Group discussion also improves better understanding of the given topic. It will motivate them to read more. Students also agreed that CBL helped them to memorize the information easily and also increased their group interaction and made clinical learning easier and enjoyable. This method also increased their sensitivity towards solving patient's problem. It was also observed that CBL not only enhances subject knowledge but also helped the students towards good diagnosis, ideal application of pharmacological intervention, good communications, listening skills, counselling, team work and also leadership skills. But when the results were out we had a clear winner on our hands and that was PBL. The students put in their hard work to complete the tasks and that is where they win.

Both CBL and routine teaching have their own places in Medicine teaching. They are both effective. The only difference is the results that we found. The perception scores of the students were better in CBL whereas the results were better in PBL.

\section{Conclusion}

In our study there is a significant difference between the perception scores. The students were better interested in the clinical based learning.

\section{References}

1. Saha R, Das Shukla, Kaur IR. Towards the innovation for microbiology curriculum change: Students ${ }^{\text {ee }}$ perception. J Indian Med Assoc 2012;110:563-6.

2. Medical Council of India- Vision 2015. New Delhi: MCI, 2011.

3. Bhadra UK. Medical education in India: Current issues and challenges. J Indian Med Assoc 2013;111:84-5.

4. Karaman S, Celik S. An exploratory study on the perspectives of prospective computer teachers following project-based learning. International Journal of Technology \& Design education 2008;18(2):203-15.

5. Cheryl AE. Promoting student-centered learning in experiential education. Journal of Experiential Education 2004;27(2)141-60.

6. Singh S, Singh P, Trivedi S. Application Based Learning Through Hospital Projects for Teaching Microbiology to Medical Students. NJIRM 2011;2(3):11-16.

7. Deb T, Singh R, Mukhopadhyay K. Students ${ }^{\text {ee }}$ perception and practice in learning basic pharmacology through a "Project Based Learning" programme. IJRRMS 2013;3(2):28-31.

8. Mattar SG, Alseidi AL, Jones DB, Jeyarajah DR, Swanstrom LL, Aye RW et al. General surgery 
residency inadequately prepares trainees for fellowship: Results of a survey of fellowship program directors. Annals of Surgery 2013;258(3):440-9.

9. DiCarlo SE. Too much content, not enough thinking, and too little FUN!. Adv Physiol Educ 2009;33(4):25764.

10. Carvalho H. A group dynamic activity for learning the cardiac cycle and action potential. Advan Physiol Edu 2011;35(3):312-3. 